\title{
PELATIHAN KOMUNIKASI SISBAR UNTUK HANDOVER ANTARA PERAWAT DAN DOKTER DI SANTOSA HOSPITAL BANDUNG CENTRAL (SHBC)
}

DOI: https://doi.org/10.33024/jkpm.v4i5.4209

\author{
Asep Badrujamaludin ${ }^{1 *}$, Fauziah Rudhiati ${ }^{2}$, Hemi Fitriani ${ }^{3}$, Oktovina Yesayas ${ }^{4}$, \\ Sri Wahyuna ${ }^{5}$, Budiman ${ }^{6}$, Dedi Supriadi ${ }^{7}$ \\ ${ }^{1}$ Program Studi Keperawatan D3, STIKES Jenderal A. Yani Cimahi \\ ${ }^{2}$ Program Studi Keperawatan S2, STIKES Jenderal A. Yani Cimahi \\ ${ }^{3}$ Program Studi Keperawatan S1, STIKES Jenderal A. Yani Cimahi \\ ${ }^{4}$ Senior Manager Keperawatan, Santosa Hospital Bandung Central \\ ${ }^{5}$ Manager Mutu dan Pengembangan, Santosa Hospital Bandung Central \\ ${ }^{6}$ Program Studi Kesehatan Masyarakat S1, STIKES Jenderal A. Yani Cimahi \\ ${ }^{71}$ Program Studi Keperawatan D3, STIKES Jenderal A. Yani Cimahi
}

Disubmit: 15 April 2021 Diterima: 03 Mei 2021 Diterbitkan: 30 September 2021

Email: dru.stikesr@gmail.com

\begin{abstract}
ABSTRAK
Komisi bersama Amerika serikat antara tahun 1995 sampai 2006 menyebutkan bahwa Kesalahan dalam komunikasi adalah penyebab utama peristiwa 2500030000 kejadian buruk menyebabkan cacat permanen $11 \%$ kejadian buruk ini adalah karena masalah komunikasi yang berbeda 6\% (WHO, 2007). Di Indonesia data tentang kejadian tidak diharapkan (KTD) apalagi kejadian nyaris cedera (KNC) masih langka, namun di lain pihak terjadi peningkatan tuduhan "mal praktek". Komunikasi effectif adalah salah satu Sasaran keselamatan pasien, unsur yang utama dari layanan asuhan ke pasien. Santosa Hospital Bandung Central (SHBC) menggunakan komunikasi SBAR dalam komunikasi antara perawat dengan dokter dalam handover, tapi masih ada unsur yang kurang dalam komponen mengenalakan diri perawat saat menelpon dokter dan juga terkait dengan aspek rekomendasi dan dokumentasi dalam catatan keperawatan. Melihat hal ini, pentingnya penerapan kominikasi yang effectif antara perawat dan dokter yang belum konsisten dalam penerapan komunikasi SBAR ini, maka diadakan pelatihan SISBAR ( Salam Introduction Situation Background Asessment dan Recommendation). Pelatihan ini menggunakan aplikasi zoom meeting dan langsung. Pelatihan pengabdian ini di fasilitasi oleh Pendidikan STIKES A Yani, Departemen keperawatan SHBC dan Diklat SHBC. Pelatihan ini melibatkan 35 orang, terdiri dari KaUnit di lingkungan SHBC, $\mathrm{Cl}$ dan Penanggung Jawab (PJ) tim di tiap Ruangan. Dengan melibatkan mereka di harapkan setelah pelatihan akan didapatkan hasil yang signifikan dalam proses pelaporan SISBAR ini. Dari hasil pengabdian masyarakat ini terkait pelatihan ini didapatkan hasil yang baik pengetahaun SISBAR, juga peningkatan terkait pelaksanaan SISBAR di ruangan juga role play pembuatan vidio SISBAR yang sudah baik dan observasi langsung pada 20 orang di ruang perawatan.
\end{abstract}

Kata Kunci : SISBAR, Kemunikasi efectif, Handover 


\begin{abstract}
The United States Joint Commission between 1995 and 2006 states that communication errors are the main cause of 25,000-30000 adverse events causing permanent disability $11 \%$ of these adverse events are due to communication problems about $6 \%$ (WHO, 2007). In Indonesia, data on unexpected incidents (KTD) especially near-injury incidents (KNC) are still scarce, but on the other hand, there is an increase in accusations of "malpractice". Effective communication is one of the goals of patient safety, a major element of patient care. Santosa Hospital Bandung Central (SHBC) uses SBAR communication in communication between nurses and doctors in handovers, but there are still elements that are lacking in the component of recognizing nurses when calling doctors and also related to aspects of recommendations and documentation in nursing records. Seeing this, the importance of implementing effective communication between nurses and doctors who have not been consistent in implementing SBAR communication, a SISBAR training (Salam Introduction Situation Background Assessment and Recommendation) was held. This training uses the zoom meeting application and direct in ward. This community service training was facilitated by STIKES Jenderal A Yani Cimahi, SHBC Nursing Department, and SHBC Education and Training. This training involved 35 people, consisting of the Unit in the $\mathrm{SHBC}, \mathrm{Cl}$, and Person in Charge (PJ) team in each wards. By involving them, it is hoped that after the training there will be significant results in the SISBAR reporting process. From the results of this community service related to this training, there were good results in SISBAR knowledge, as well as improvements related to the implementation of SISBAR in the wrads as well as the role play of making good SISBAR videos and direct observation of 20 people in the wards.
\end{abstract}

Keywords: SISBAR, Effective Communication, Handover

\title{
1. PENDAHULUAN
}

Indonesia Keselamatan pasien telah menjadi isu dunia yang perlu mendapat perhatian bagi sistem pelayanan kesehatan. Tahun 2000 Institute of Medicine (IOM) di Amerika Serikat menerbitkan laporan yang dilakukan di rumah sakit di Utah dan Colorado ditemukan Kejadian Tidak Diduga (KTD) sebesar 2,9\% dan 6,6\% diantaranya meninggal, sedangkan dirumah sakit yang ada di New York ditemukan 3,7\% kejadian KTD dan 13,6\% diantaranya meninggal. Angka kematian akibat KTD pada pasien rawat inap di seluruh Amerika Serikat yang berjumlah 33,6 juta per tahun berkisar 44.000 sampai 98.000 dilaporkan meninggal setiap tahunnya dan kesalahan medis menempati urutan kedelapan penyebab kematian di Amerika Serikat. Publikasi oleh WHO pada tahun 2004, juga menemukan KTD dengan rentang 3,2-16,6\% pada rumah sakit diberbagai negara yaitu Amerika, Inggris, Denmark, dan Australia ( Depkes RI, 2006).

Di Indonesia data tentang kejadian tidak diharapkan (KTD) apalagi kejadian nyaris cedera (KNC) masih jarang di beritakan, namun di lain pihak terjadi peningkatan tuduhan "mal praktek", yang belum tentu sesuai dengan pembuktian akhir.Sasaran keselamatan pasien tersebut meliputi ketepatan identifikasi pasien, peningkatan komunikasi yang efektif, peningkatan keamanan obat yang perlu diwaspadai, kepastian tepat-lokasi, tepat prosedur, tepat-pasien operasi, pengurangan risiko infeksi terkait pelayanan kesehatan, dan pengurangan risiko 
pasien jatuh. Dari enam sasaran keselamatan pasien, unsur yang utama dari layanan asuhan ke pasien adalah komunikasi efektif . Komunikasi efektif sangat dipengaruhi oleh karakteristik individu itu sendiri diantaranya adalah umur, jenis kelamin dan lama kerja(Rokhmah \& Anggorowati, 2017).

Komunikasi terhadap berbagai informasi mengenai perkembangan pasien antar profesi kesehatan di rumah sakit merupakan komponen yang fundamental dalam perawatan pasien ( Riesenberg, 2010). Alvarado, et al (2006), mengungkapkan bahwa ketidakakuratan informasi dapat menimbulkan dampak yang serius pada pasien, hampir 70\% kejadian sentinel yaitu kejadian yang mengakibatkan kematian atau cedera yangserius di rumah sakit disebabkan karena buruknya komunikasi.

Pernyataan di atas sejalan dengan pernyataan Angood (2007) yang mengungkapkan bahwa berdasarkan hasil kajian data terhadap adanya adverse event, near miss dan sentinel event di rumahsakit, masalah yang menjadi penyebab utama adalah komunikasi. Komunikasi efektif adalah unsur utama dari sasaran keselamatan pasien karena komunikasi adalah penyebab pertama masalah keselamatan pasien (patient safety). Komunikasi yang efektif yang tepat waktu, akurat, lengkap, jelas, dan dipahami oleh penerima mengurangi kesalahan dan meningkatkan keselamatan pasien. Maka dalam komunikasi efektif harus dibangun aspek kejelasan, ketepatan, sesuai dengan konteks baik bahasa dan informasi, alur yang sistematis, dan budaya. Komunikasi yang tidak efektif akan menimbulkan risiko kesalahan dalam pemberian asuhan keperawatan. Sebagai contoh kesalahan dalam pemberian obat ke pasien, kesalahan melakukan prosedur tindakan perawatan. Mencegah terjadinya risiko kesalahan pemberian asuhan keperawatan maka perawat harus melaksanakan sasaran keselamatan pasien yaitu komunikasi efektif. Untuk itu diperlukan pendekatan sistematik untuk memperbaiki komunikasi tersebut salah satunya dengan cara komunikasi teknik SISBAR ( Salam, Introduction, Situation, Background, Asessment, Recommendations).

Hasil survey sebanyk 330 survey dan interview yang di lakukan Aldrich (2009) terhadap Pemberi pelayanan kesehatan medik dan non medik, pasien, staff dan orang ynag trensfer pasien mengatakan bahwa Elemen ISBAR adalah paling baik yaitu sederhana, mudah di ingat dan mudah di bawa. Selain itu, staff lebih percaya diri dalam memeberikan dan menerima hand over dan audit catatan medik mengindikasikan peningkatan kualitas informasi yanga ada. Dan ISBAR ini sudah di implementasikan diarea the Hunter New England Areas Kesehatan di Wilayah NSW Dinas Kesehatan, Australia. Kemudian di kuatkan oleh hasil penelitian terbaru yang di lakukan Ramasubbu tahun 2017. Hasil penelitian Ramasubbu et.al (2017) mengatakan bahwa pengenalan dalam standarisasi templet hand over ISBAR (Introduction, Situation, Background, Asessment, Recommendations) telah meningkatkan kualitas dan keselamatan pasien dari handover diantara dokter di ICU dan IGD.

Dengan melihat Fenomena yang sering terjadi di Indonesia dan belum adanya standard komunikasi yang sama di antara komunikasi antar petugas kesehatan di rumah Sakit di Indonesia dan khususnya di daerah Bandung dan Cimahi, dan Pentingnya standard komunikasi yang jelas untuk keselamatan pasien dan mengurangi reskio terjadinya Komunikasi yang tidak effective, maka peneliti tertarik untuk meneliti tehnik komunikasi yang tepat dan mengaplikasikan tehnik komunikasi SISBAR dengan menambahkan Salam dalam ISBAR di Santosa Hospital Bandung Central. 


\section{MASALAH}

Analisis situasi di SHBC sudah menggunakan komunikasi SBAR, tapi dalam penerapannya masih belum di terapkan secara maksimal. Perawat hanya handover atau laporan ke dokter dengan langsung menanyakan langsung apa advisenya. Ini akan mengakibatkan permaslaahan dalam komunikasi dengan dokter.Masalah lainnya, terkadang perawat saat melakukan laporan kepada dokter lupa untuk memperkenalkan diri dan juga kadang lupa mengucapkan salam. Oleh karena itu perlu kiranya dilakukan pelatihan yang fokus pada komunikasi anatara perawat dan dokter. Dengan melihat fenomena ini maka di lakukan pengabdian masyarakat dengan memberikan pelatihan terkiat dengan komunikasi yang konsisten dengan memberikan komunikasi SISBAR.

SISBAR ini sudah di lakukan penelitian dengan hasil yang effective dalam pemberian komuniasi yang konsisten. Sangat berbahaya kalau seandainya perawat hanya memebrikan atau menanyakan masukan dari dokter terkait dengan pasien. Ini juga bagian dalam keselamatan pasien khususnya komunikasi yang effective. Permasalahan lain adalah Pentingnya melakukan ini karena pelatihan komunikasi SISBAR pernah dilakukan di SHBC 5 tahun yang lalu. Sehaingga dengan adanya perawat baru dan juga perawat lama yang belum terpapar dengan pemahaman yang sama dalam komunikasi SISBAR ini.

Dalam Rangka mensukseskan 6 sasaran keselamatan pasien salah satunya dalam komunikasi, perlu ada upaya yang nyata dalam memeprsiapkan perawat agar lebih mengetahui sebagai profesi yang profesioanl khususnya dalam amalsaha pelaporan atau handover kepada profesi lain yang salah satunya profesi dokter. Upaya kegiatan-kegiatan yang dilakukan dalam pengabdian ini, yaitu dengan melakukan pelatihan dan workshop terkait SISBAR. Selain itu juga pembuatan vidio dari masing masing peserta untuk melakukan komunikasi dengan menggunakan SISBAR. Sehingga perawat akan terbiasa dengan menggunakan komunikasi ini, dan out putnya menjadikan pasien mendapatkan perawatan yang maksimal dengan komunikasi yang baik.

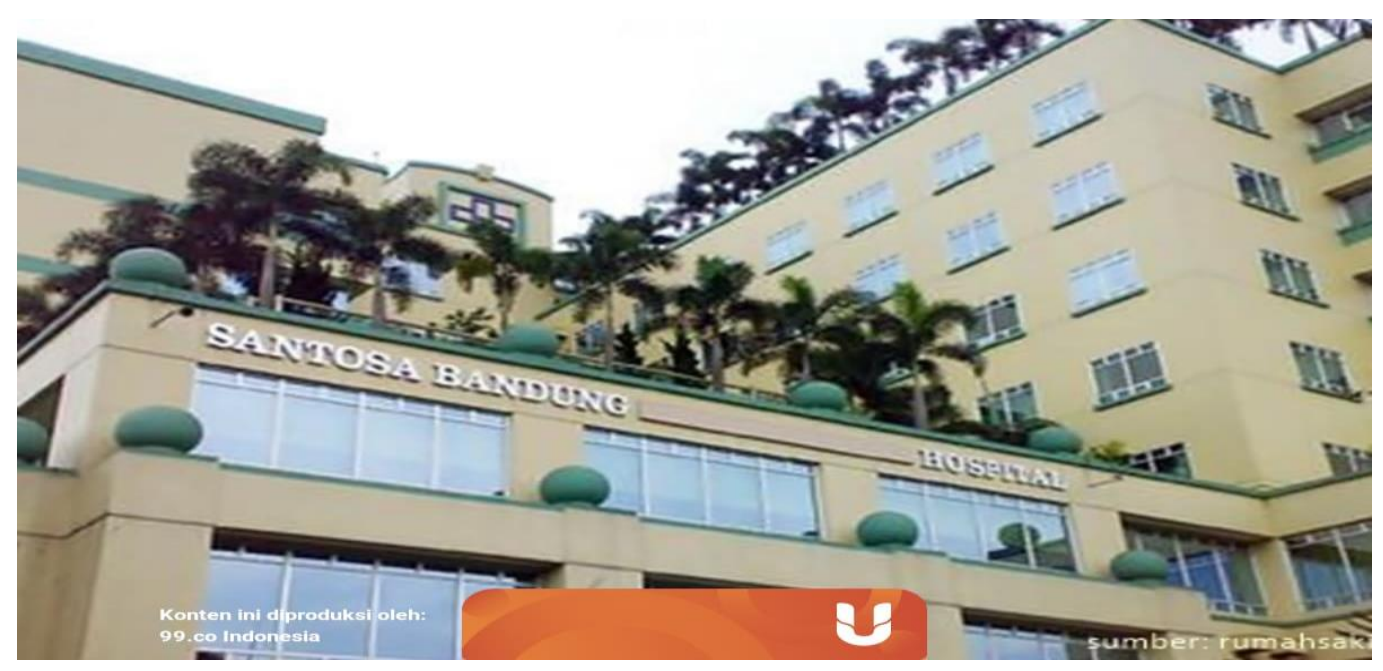




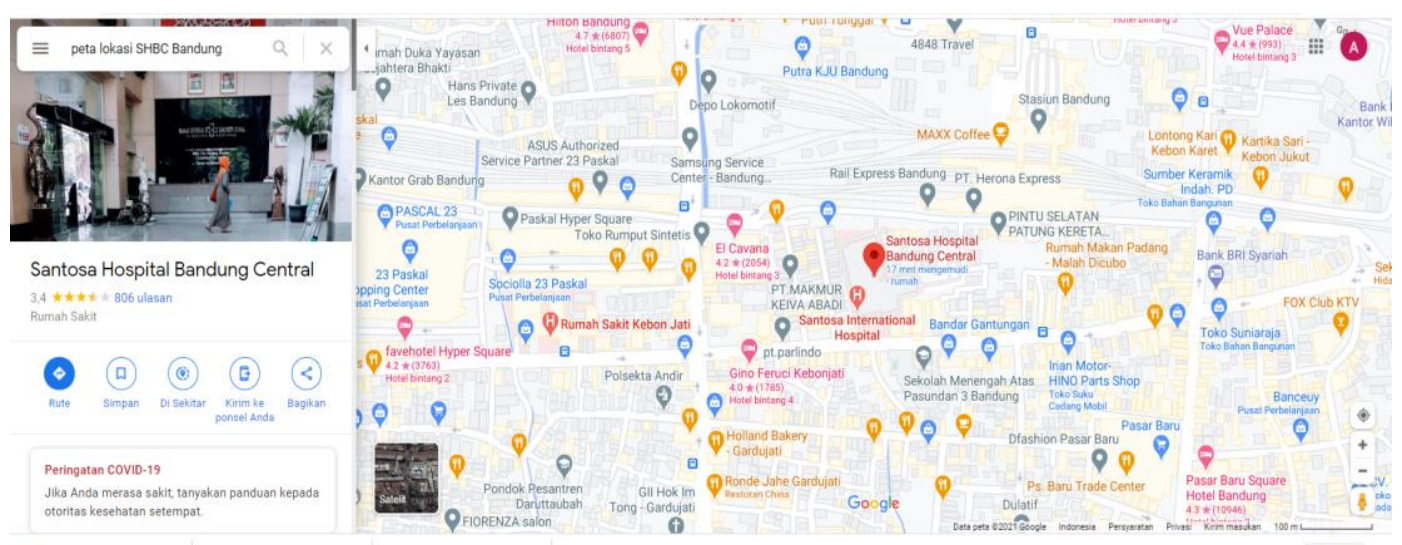

Gambar 2.1 Peta Lokasi Kegiatan Pengbdian Kepada Masyarakat.

\section{METODE}

a. Tujuan Persiapan

Tahap persiapan dari kegiatan adalah pembuatan pre planning, persiapan penyajian dalam bentuk pelatihan, simulasi komunikasi SISBAR, penyiapan media baik Online via zoom dan juga Audotorium di SHBC. Pembuatan materi Pelatihan dengan materi komunikasi Effective dan juga materi komunikasi SISBAR.

\section{b. Tahap pelaksanaan}

Acara ini dengan koordinasi dengan Bidang Keperawatan dan Bidang Pendidikan dan Pelatihan SHBC. Setelah itu di buat tim koordinasi antara perwakilan STIKES A yani dan SHBC. Perwakilan dari diwakili oleh 4 orang yang juga di tugaskan untuk memberikan pelatihan SISBAR, dan dari SHBC 2 orang dari departemen keperawatan dan 2 orang dari DIKLAT. Peserta pelatihan ini terdiri dari para Ka unit dan $\mathrm{Cl}$ di lingkungan SHBC. Dan dalam tahap akhir melakukan simulasi dan praktik langsung yang di upload dalam bentuk vidio SISBAR. Untuk observasi langsung perwakilan Kepala tim dan Penanggung jawab Shift dari 2 ruang bedah, ruby barat dan Ruby Timur sebanyak 20 orang perawat.

Pelatihan ini menggunakan media daring via Zoom saat pemaparan materi Komunikasi Effective dan Komunikasi SISBAR, selain itu dalam proses pengiriman vidio SISBAR langsung di kirim melalui Gdrive. Setalah itu dilakukan observasi langsung pelaksanaan komunikasi SISBAR di ruangan langsung dengan mengisi lembar observasi SISBAR.

\section{c. Evaluasi}

\section{Struktur}

Peserta hadir dalam pelatihan SISBAR ini sebanyak 34 orang yang sering melakukan laporan ke dokter yaitu Kepala unit, $\mathrm{Cl}$, Kepala Tim dan Penanggung Jawab Shift . Untuk Observasi langsung di lakukan di ruang Ruby Barat dan Ruby Timur kepada Penanggung jawab shift dan Kepala Tim . Setting tempat dan juga media Zoom dan juga di google drive untuk upload vidio sudah baik. Dan juga vidio yang di berikan oleh peserta sudah baik dalam Salam, hal mengenalkan diri juga dalam rekomendasi dari perawat untuk pasien yang di asuhnya kepada dokter 
yang merawat. Perawat juga sudah melakukan dengan baik dengan dibuktikan oleh hasil observasi terkait laporan atau handover kepada dokter.

ii. Proses

Pelaksanaan kegiatan dilakukan selama 2 minggu dan Sesuai dengan jadwal yang telah direncanakan. Untuk daring via zoom di lakukan sehari yaitu pada tanggal 18 Desember 2020.

\section{HASIL DAN PEMBAHASAN}

Pelaksanaan Observasi di lakukan kepada kepala tim daan penanggung jawab shift di 2 ruang medikal bedah Ruby Barat dan Ruby Timur RS Santosa bandung sebanyak 20 orang. Para perawat ini di dominasi oleh perawat perempuan dengan pendidikan D3 keperawatan, dan sebagian kecil pendidikan profesi ners. Mereka awalnya di lakukan pre test dan juga pelatihan terkait komunikasi efective dan komunikasi SISBAR dalam pelaporan atau handover kepada dokter. Setelah itu dilakukan simulasi mandiri oleh peserta dengan melakukan komunikasi langsung vidio dg menggunakan SISBAR dan kemudian vidio itu dikirimkan kepada panitia untuk dilakukan evaluasi. Setelah itu di minggu kedua perawat yang sudah pelatihan di observasi oleh fasilitator secara langsung. Observasi langsung ini dengan mengisi form observasi SISBAR saat melihat pelaporan pasien kemudian dilanjutkan dengan melihat pendokumentasian langsung di Catatan Perkembangan Pasien Terintegrasi (CPPT) di status pasien. Setelah itu di lakukan post test di akhir sebelaum dilakukan obervasi. Dari hasil observasi ini di lihat ada peningkatan dalam komunikasi dengan menggunakan SISBAR setelah di berikan pelatihan di ruang Ruby Barat dan Ruby Timur. Hasil ini juga di perkuat oleh penelitian yang dilakukan Badrujamaludin dan Kumala (2019) terkait effectivenya komunikasi ISBAR yang di terapkan di RS Cibabat Cimahi. Ini membuktikan bahwa pelatihan dan pengabdian masyarakat ini bermanfaat dan dapat diaplikasikan secara langsung di RS SHBC Bandung. Ini juga di pengaruhi oleh berbagai faktor dalam memahami perawat untuk melakukan komunikasi ini. Selain memberikan penyuluhan perlu juga di lakukan role play yang bisa mereka lihat langsung.

Juga dengan menggunakan komunikasi yang jelas SISBAR( salam, Introduction, Situation, Background, Asesment dan Rekomendation). Dengan menggunakan komunikasi ini yang mudah di ingat dan juga di berikan format pelaporan memudahkan perawat dalam melakukan pelaporan terhadap dokter. Juga ini akan memberikan kemudahan dalam komunikasi anarat profesional dan juga akan memnerikan dampak kepada keselamatan pasien. Enam unsur sasaran keselamatan pasien yang utama dari layanan asuhan ke pasien adalah komunikasi efektif. Menghindari risiko kesalahan dalam pemberian asuhan keperawatan pasien dan meningkatkan kesinambungan perawat dan pengobatan maka diharuskan menerapkan komunikasi efektif ( Fitri, 2011). Komunikasi adalah penyebab pertama masalah keselamatan pasien (patient safety). Komunikasi merupakan proses yang sangat khusus dan berarti dalam hubungan antar manusia. Komunikasi yang efektif yang tepat waktu, akurat, lengkap, jelas, dan dipahami oleh penerima mengurangi kesalahan dan meningkatkan keselamatan pasien (Supinganto, 2015).

Berikut gambar pelaksanaan kegiatan: 

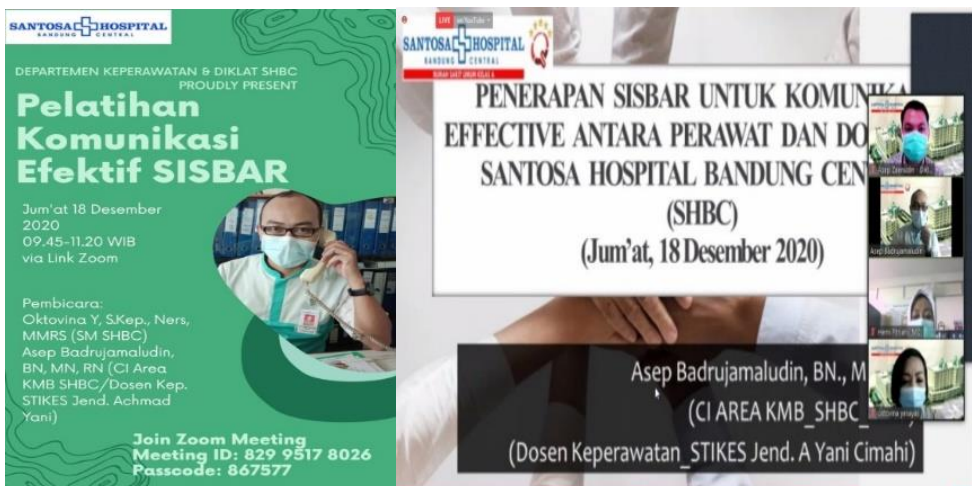

Gambar 2.1 Foto flayers Kegiatan Pelatihan SISBAR

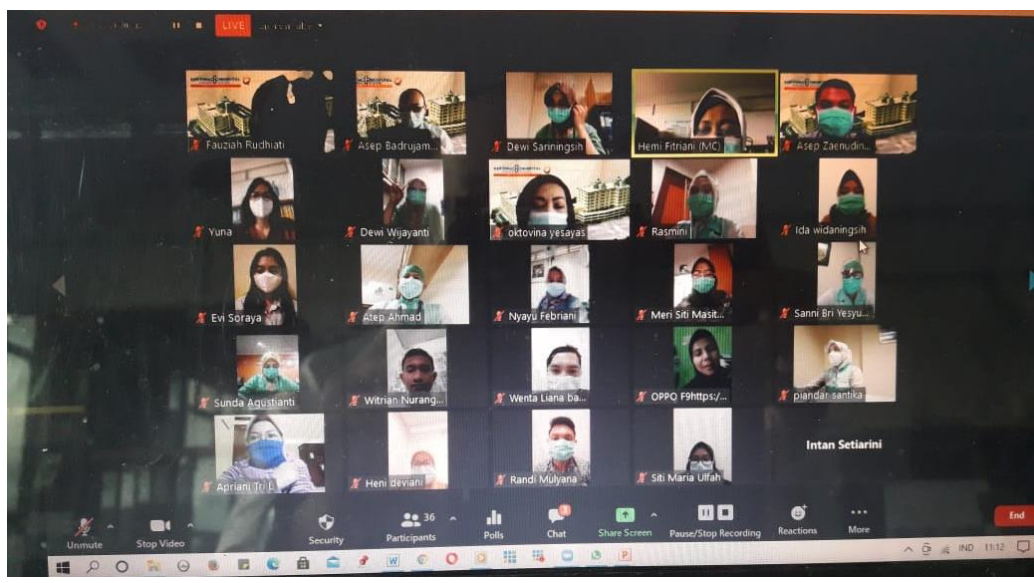

Gambar 2.2 Pembicara dan peserta pelatihan
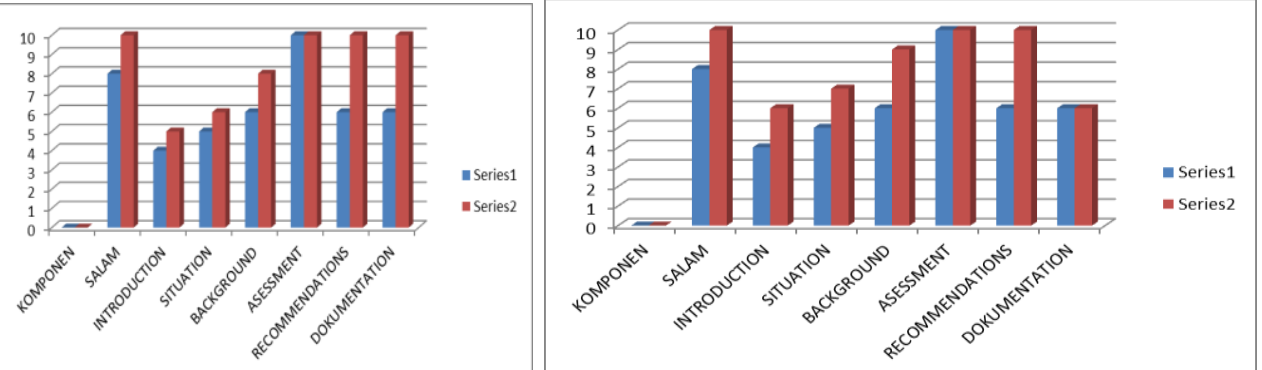

Gambar 2.3 hasil Observasi Pre Post Komunikasi SISBAR Ruby Barat dan Timur

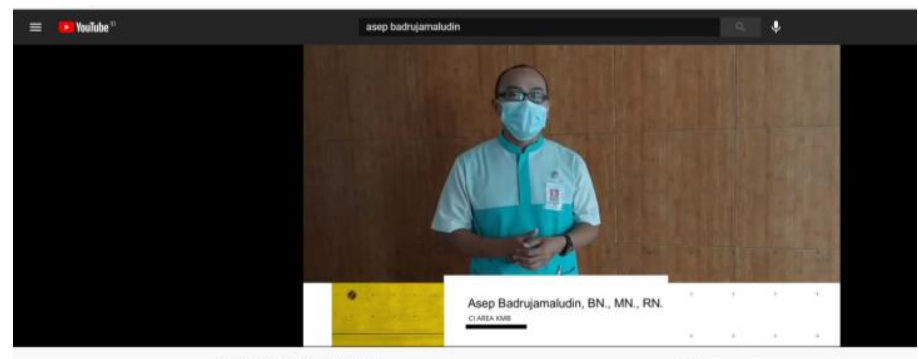

Gambar 2.4 Role play SISBAR 


\section{KESIMPULAN}

Kegiatan ini dapat dilakukan oleh para penanggung jawab Shift dan kepala tim sebagai salah satu solusi dalam pelaporan yang effective, mudah dan terstruktur dengan menggunakan komunikasi SISBAR. Komunikasi SISBAR ini juga merupakan terobosan baru dari hasil pelatihan dan penelitian yang outputnya secara nyata terlihat dari hasil pelatihan ini. Dan kegiatan SISBAR komunikasi ini bermanfaat dan bisa diterapakan secara menyeluruh khususnya di rumah sakit Santosa bandung. Ini juga akan memberikan nilai postif perawat sebagai profesi yang profesional dan akan lebih percaya diri bagi perawat dan hal komunikasi dengan profesi lain.

\section{DAFTAR PUSTAKA}

Aldrich R, Duggan A, Lane K, Nair K, Hill KN. (2009). ISBAR revisited: identifying and solving barriers to effective clinical handover in inter-hospital transfer: final project report. Newcastle: Hunter New England Health

Aldrich, R. National Clinical Handover Initiative, Hunter New England, NSW Health. (2009). ISBAR Revisited: Identifying and solving Barriers to effective clinical handover in inter-hospital transfer. Australian Commision on Safety and Quality in Health Care.

Alvarado, K., Lee, R., Christoffersen, E., Fram, N., Boblin, S., Poole, N. (2006). Transfer of accountability: transforming shift handover to enhance patient safety. Health care quarterly Dikses pada tanggal 18 Februari 2020 dari http://web.ebscohost.com/ehost/resultadvanced.

Badrujamaludin, A., \& Kumala, T. F. (2019). Penerapan Introduction, Situation, Background, Assessment and Recommendation (ISBAR) untuk komunikasi efektif antara perawat dan dokter di Rumah Sakit Umum Daerah Cibabat Kota Cimahi. Holistik Jurnal Kesehatan, 13(4), 306-317.

DepKes RI. (2008). Panduan nasional keselamatan pasien rumah sakit (patient safety). ed: 2. Jakarta.

Fitria, C. (2011). Efektivitas pelatihan komunikasi SBAR dalam meningkatkan motivasi dan psikomotor perawat ruang medikal bedah Rumah Sakit PKU Muhammadiyah Surakarta. Yogyakarta: Program Magister Manajemen Rumah Sakit.

Ramasubbu, B., Stewart, E. \& Spiritoso, R. (2017). Introduction of the identification, situation, background, asessment, recommendations tools to improve the quality of information transfer during medical handover in intensive care. Journal of the Intensive Care Society 2017, vol. 18(1) 1723.

Riesenberg LA, Leitzsch J, Cunningham JM. (2010). Nursing handoffs: a sistematic review of the literatuter. Am $J$ Nurs. 110(4):24-34; doi: 10.1097/01.NAJ.0000370154.79857.09.

Rokhmah, N. A., \& Anggorowati, A. (2017). Komunikasi efektif dalam praktek kolaborasi interprofesi sebagai upaya meningkatkan kualitas pelayanan. JHeS (Journal of Health Studies), 1(1), 65-71.

Supinganto, A.,Mulianingsih, M dan Suharmanto. (2015). Identifikasi Komunikasi Efektif SBAR (Situation, Background, Assesment, Recommendation) Di RSUD Kota Mataram. STIKes Yarsi Mataram. Tersedia dalam : <stikesyarsimataram.ac.id> (diakses 5 April 2019).

WHO (2007). Patient Safety Solutions; Communication during patient hand-overs http://www.who.int/patientsafety/solutions/patientsafety/PS-

Solution3.pdf 